\title{
GAMBARAN PROSES PENGAMBILAN KEPUTUSAN UNTUK MENJADI MISIONARIS
}

\author{
Stevanie Laurens ${ }^{1}$, Raja Oloan Tumanggor ${ }^{2}$ \\ ${ }^{1}$ Fakultas Psikologi, Universitas Tarumanagara Jakarta \\ Email: stevanie.705160047@stu.untar.ac.id \\ ${ }^{2}$ Fakultas Psikologi, Universitas Tarumanagara Jakarta \\ Email: rajat@fpsi.untar.ac.id
}

Masuk : 17-04-2020, revisi: 29-04-2021, diterima untuk diterbitkan : 30-04-2021

\begin{abstract}
The decision making process of becoming a missionary is not an easy task to do because it needs a lot of consideration. Every decision making processes usually need to go through several stages, it also applies in the decision making process to become a missionary. When someone live as a missionary, they might face a lot of challenges and difficulties that could even make them quit mission forever. The challenges for most missionaries include financial difficulties, desperation and feel unable to do things, or even tiredness. This research aimed to give more information regarding the decision making process of becoming a missionary that includes all of the stages that each of them go through in their decision making process and also the factors that influence their decision making. This type of research is non experimental with quantitative research methods. Data retrieval in this study using interview techniques in depth interview. There are seven stages of participant decision making before deciding to become a missionary. The participants of this research are five Indonesian missionary who serve at several cities in Indonesia and also in another country. It is known that the study participants were most accurately informed about missionaries because they were active in serving in the church and participated in activities such as short theological schools, etc. From the result of this research, we could see that the decision making process of becoming a Christian missionary also follows the decision making steps.
\end{abstract}

Keywords: decision making, missionary

\begin{abstract}
ABSTRAK
Proses pengambilan keputusan untuk menjadi misionaris bukan hal yang mudah untuk dilakukan karena memerlukan banyak pertimbangan. Setiap proses pengambilan keputusan biasanya melalui beberapa tahapan, begitu pula dengan proses pengambilan keputusan untuk menjadi seorang misionaris. Ketika seseorang menjalani kehidupan sebagai misionaris maka mereka akan menghadapi banyak tantangan dan kesulitan yang bahkan bisa menyebabkan mereka keluar dari misi misalnya tekanan dalam hal finansial, memiliki perasaan tidak mampu, atau merasa kelelahan. Penelitian ini bertujuan untuk memberikan gambaran proses pengambilan keputusan yang terjadi pada orang yang menjadi misionaris meliputi seluruh tahapan yang dilalui serta faktor apa yang paling memengaruhi pengambilan keputusan tersebut sehingga dapat membantu pembaca, khususnya calon misionaris Kristen, ketika mau melakukan pengambilan keputusan yang penting. Jenis penelitian ini adalah non eksperimental dengan metode penelitian kuantitatif. Pengambilan data dalam penelitian ini menggunakan teknik wawancara in depth interview. Terdapat tujuh tahapan pengambilan keputusan partisipan sebelum memutuskan diri menjadi seorang misionaris. Partisipan penelitian ini terdiri dari lima orang misionaris Kristen asal Indonesia yang melayani di berbagai kota di Indonesia dan juga di luar negeri. Diketahui bahwa partisipan penelitian paling banyak mendapat informasi akurat terkait misionaris karena aktif dalam melayani di gereja dan mengikuti berbagai kegiatan seperti sekolah teologi singkat, dan lain-lain.Berdasarkan hasil penelitian, pengambilan keputusan untuk menjadi misionaris dilakukan sesuai dengan tahapan pengambilan keputusan.
\end{abstract}

Kata Kunci: pengambilan keputusan, misionaris

\section{PENDAHULUAN}

\section{Latar Belakang}

Setiap orang pasti memiliki permasalahan dalam kehidupannya. Dalam menyelesaikan permasalahan atau konflik tersebut, perlu dilakukan pengambilan keputusan. Pengambilan keputusan dijelaskan oleh DuBrin (1978) sebagai suatu kondisi yang disebabkan karena ada ketidaksesuaian antara hal ideal yang diinginkan seseorang dengan kenyataan yang terjadi. DuBrin 
(2012) juga menjelaskan bahwa pengambilan keputusan merupakan proses pemilihan berbagai alternatif. Terkait dengan proses pengambilan keputusan, Halpern (2014) menjelaskan bahwa terdapat tujuh tahapan ketika seseorang mau melakukan pengambilan keputusan yakni (1) mengidentifikasi, mengenal, dan membentuk keputusan; (2) menyusun alternatif; (3) mengevaluasi alternatif; (4) menyeleksi alternatif; (5) melakukan evaluasi, membentuk, dan menyusun ulang alternatif; (6) membuat keputusan dan melakukan hasil keputusan; dan (7) mengevaluasi hasil. Tahapan mencari solusi alternatif dianggap sebagai salah satu tahap yang penting dalam pengambilan keputusan dalam berbagai penelitian yang dilakukan terkait pengambilan keputusan (Siebert, Kunz, \& Rolf, 2019).

Dalam menjalani tahapan-tahapan pengambilan keputusan tersebut, terdapat banyak faktor yang dapat mempengaruhi seseorang sebelum pada akhirnya mengambil keputusan. DuBrin (2012) menyebutkan beberapa faktor yang mempengaruhi pengambilan keputusan termasuk intuisi, kepribadian dan kecerdasan kognitif, kecerdasan emosi, kualitas dan aksesibilitas informasi, pertimbangan politis, tingkat keyakinan, krisis dan konflik, nilai-nilai, serta kecenderungan seseorang untuk menunda. Ketika ingin melakukan pengambilan keputusan, hal- hal tersebut juga dialami oleh para calon misionaris.

Misionaris didefinisikan dalam Kamus Besar Bahasa Indonesia (KBBI) sebagai orang yang melakukan pemberitaan warta Injil kepada orang lain yang belum mengenal Kristus. Selain itu, Tumanggor (2014) menjelaskan bahwa misionaris berasal dari kata bahasa Latin missionarius yang berarti orang yang diutus dan bertugas untuk melakukan misi.

Penelitian yang dilakukan oleh Hibbert, Hibbert, dan Silberman (2015) terkait bagaimana perjalanan para misionaris Kristen di Australia menunjukkan beberapa faktor yang mempengaruhi keputusan mereka untuk menjadi misionaris. Tiga faktor utama yang dapat mempengaruhi seseorang untuk mengambil keputusan menjadi seorang misionaris Kristen menurut penelitian tersebut adalah kejadian dan pengalaman; aktivitas; serta sikap dan kepercayaan. Namun ketika menjalankan tugasnya, penelitian yang ada menunjukkan bahwa terdapat berbagai permasalahan yang dihadapi oleh seorang misionaris.

Penelitian yang dilakukan oleh Bosch (2014) melibatkan sekitar 2.086 partisipan yang merupakan misionaris dari berbagai daerah menunjukkan terdapat konflik dan tekanan yang dialami oleh misionaris yang melakukan pemberitaan Injil ini. Hasil penelitian tersebut menunjukkan bahwa terdapat sepuluh permasalahan yang menjadi tekanan berat bagi misionaris yakni kebutuhan anak, keadaan orangtua yang semakin lanjut usia, masalah dengan rekan kerja, perasaan tidak mampu, kekurangan sumber daya manusia, tekanan budaya, mempertahankan disiplin spiritual, batasan bahasa, kelelahan dalam bekerja, serta tekanan finansial. Dari kesepuluh permasalahan ini, hal yang paling menjadi tekanan bagi sebagian besar misionaris adalah tekanan finansial yang mereka alami yakni mencapai $30 \%$. Berbagai permasalahan yang dialami oleh misionaris ini bahkan dapat mendorong mereka hingga keluar dari misi.

Populasi orang Kristen merupakan populasi kedua terbanyak di Indonesia yakni sebesar 7\% (Oslo dalam Hoon, 2013). Hal tersebut tentunya tidak terlepas dari peran misionaris-misionaris yang melakukan pengabaran Injil baik di Indonesia maupun di negara-negara lainnya. Meskipun demikian, penelitian-penelitian dari sisi psikologi dengan topik terkait misionaris masih sangat sulit untuk ditemukan di Indonesia. 
Oleh karena hal-hal seperti banyaknya misionaris yang keluar dari kegiatan misi setiap tahunnya serta masih sedikit penelitian di Indonesia yang membahas tentang proses pengambilan keputusan pada misionaris membuat peneliti terdorong untuk mengkaji lebih lanjut mengenai Gambaran Proses Pengambilan Keputusan untuk Menjadi Seorang Misionaris. Melalui penelitian ini diharapkan setiap orang yang membacanya, terutama para calon misionaris Kristen, dapat lebih memahami bagaimana gambaran proses pengambilan keputusan sehingga dapat bermanfaat untuk proses pengambilan keputusan mereka secara pribadi.

\section{Rumusan Masalah}

Berdasarkan latar belakang masalah yang telah disusun, rumusan masalah yang akan diteliti adalah, bagaimana gambaran proses pengambilan keputusan untuk menjadi misionaris?

\section{METODE PENELITIAN}

Penelitian ini merupakan jenis penelitian non eksperimen dan menggunakan metode penelitian kualitatif. Pengambilan data dalam penelitian ini dilakukan dengan menggunakan teknik wawancara yakni in depth interview. Jenis penelitian ini biasanya digunakan ketika berhadapan dengan kasus-kasus yang sulit. Desain penelitian ini menggunakan desain penelitian deskriptif yakni desain penelitian yang bertujuan untuk memberikan gambaran atau informasi yang mendalam mengenai hal tertentu. Penelitian ini secara khusus membahas gambaran proses pengambilan keputusan yang dilakukan oleh seseorang untuk menjadi misionaris.

Partisipan dalam penelitian ini adalah misionaris Kristen, yakni orang-orang yang memberitakan Injil kepada orang yang belum percaya. Adapun jumlah partisipan dalam penelitian ini sebanyak 5 (lima) orang misionaris Kristen berusia 40-45 tahun. Jumlah tersebut ditentukan dengan mempertimbangkan adanya keterbatasan waktu dalam melakukan penelitian. Dalam menentukan partisipan penelitian, partisipan dipilih dengan menggunakan metode snowball sampling (teknik bola salju). Berikut merupakan gambaran data partisipan penelitian:

Tabel 1. Gambaran Data Partisipan

\begin{tabular}{|c|c|c|c|c|c|}
\hline $\begin{array}{l}\text { Partisipan } \\
\text { Penelitian }\end{array}$ & $\begin{array}{l}\text { Partisipan Pertama } \\
\text { (R) }\end{array}$ & $\begin{array}{l}\text { Partisipan Kedua } \\
\text { (H) }\end{array}$ & $\begin{array}{l}\text { Partisipan Ketig } \\
\text { (HRS) }\end{array}$ & $\begin{array}{l}\text { aPartisipan } \\
\text { Keempat (HM) }\end{array}$ & $\begin{array}{l}\text { Partisipan } \\
\text { kelima (D) }\end{array}$ \\
\hline$\overline{\text { Usia }}$ & 40 tahun & 45 & 45 tahun & 43 tahun & 40 tahun \\
\hline Status & Menikah & Menikah & Menikah & Menikah & Menikah \\
\hline Asal Daerah & Nias & Jepara & Garut & Banua & Jakarta \\
\hline Agama & $\begin{array}{l}\text { Kristen } \\
\text { Protestan }\end{array}$ & $\begin{array}{l}\text { Kristen } \\
\text { Protestan }\end{array}$ & $\begin{array}{l}\text { Kristen } \\
\text { Protestan }\end{array}$ & $\begin{array}{l}\text { Kristen } \\
\text { Protestan }\end{array}$ & $\begin{array}{l}\text { Kristen } \\
\text { Protestan }\end{array}$ \\
\hline $\begin{array}{l}\text { Pendidikan } \\
\text { Terakhir }\end{array}$ & $\begin{array}{l}\text { D3 } \\
\text { Pendidikan Kristen }\end{array}$ & $\begin{array}{l}\text { S1 Teologia } \\
\text { (S.Th) }\end{array}$ & $\begin{array}{l}\text { S1 } \\
\text { Pendidikan } \\
\text { Agama Kristen } \\
\text { (SPd.K) }\end{array}$ & $\begin{array}{l}\text { Diploma } \\
\text { Teologia } \\
\text { (Dip.Th) }\end{array}$ & $\begin{array}{l}\text { S2 } \\
\text { Psikologi } \\
\text { (M.si) }\end{array}$ \\
\hline $\begin{array}{l}\text { Lokasi Pelayanan } \\
\text { Saat Ini }\end{array}$ & Purwokerto & Purwokerto & Papua & $\begin{array}{l}\text { Depok, } \\
\text { Jawa Barat }\end{array}$ & $\begin{array}{l}\text { Korea } \\
\text { Selatan }\end{array}$ \\
\hline
\end{tabular}

Ketika peneliti telah menyelesaikan seluruh proses pengambilan data berupa wawancara, peneliti melanjutkan ke proses pengolahan dan analisa data. Proses pengolahan data pertama- tama dilakukan oleh peneliti dengan mendengarkan rekaman hasil wawancara dan membuat rekaman tersebut menjadi transkrip verbatim dengan tujuan agar hasil wawancara tersebut bisa dianalisis dan diteliti secara lebih mendalam. 
Setelah peneliti menyelesaikan seluruh transkrip verbatim dari kelima partisipan, peneliti membuat tabel coding dari masing-masing partisipan agar dapat mempermudah peneliti ketika melakukan analisa terhadap hasil data yang diperoleh. Proses analisa data dilakukan peneliti dengan menggunakan teori yang ada di Bab II. Peneliti menganalisis keseluruhan data subjek secara mendalam dan membuat tabel analisis sesuai dengan teori yang digunakan. Melalui tabel tersebut peneliti juga menganalisis perbedaan dan persamaan yang dimiliki oleh setiap subjek baik untuk tahapan proses pengambilan keputusan yang mereka alami maupun faktor-faktor yang mempengaruhi mereka dalam melakukan pengambilan keputusan mereka untuk menjadi seorang misionaris.

\section{HASIL DAN PEMBAHASAN}

Pada penelitian ini mengkaji secara mendalam bagaimana proses pengambilan keputusan yang dilakukan oleh kelima orang partisipan untuk menjadi seorang misionaris. Proses pengambilan keputusan yang dilakukan oleh partisipan penelitian sesuai dengan teori yang disebutkan oleh Halpern (2014). Pada tahap pertama yakni mengidentifikasi, mengenal, dan membentuk keputusan setiap partisipan mengalaminya pada usia yang berbeda-beda dan memiliki alasan yang berbeda pula. Ada yang mulai mengidentifikasi karena mengalami konflik, melihat kehidupan pendeta di gerejanya, maupun karena merasakan panggilan dari dalam dirinya sendiri.

Dalam melakukan penyusunan alternatif di tahap kedua, partisipan penelitian memiliki dua alternatif kecuali partisipan kelima yang berinisial D yang hanya ingin masuk sekolah teologia. Pada tahap ini tiga orang partisipan memiliki alternatif untuk menjadi misionaris atau tetap pada pekerjaannya saat itu sebagai karyawan dan satu orang partisipan memiliki alternatif untuk menjadi perawat. D yang pada saat itu tidak memiliki alternatif kemudian mengalami kebingungan setelah lulus dari sekolah teologia apakah mau menjadi misionaris, dosen, atau melakukan pekerjaan-pekerjaan lainnya.

Tahap ketiga, mengevaluasi alternatif, merupakan tahap partisipan mencari informasi dari berbagai sumber. Pada tahap ketiga ini partisipan paling banyak mendapat informasi karena mengikuti pelayanan di gereja atau terlibat dalam kegiatan seperti sekolah teologia singkat, persekutuan, dan kegiatan gerejawi lainnya. Partisipan keempat, HM, yang tidak melakukan pelayanan dan jarang ke gereja sejak SMA hanya mendapatkan sangat sedikit informasi terkait misionaris sehingga ketika akhirnya menjadi misionaris ia merasa kaget dan kecewa karena banyak hal yang tidak sesuai ekspektasinya.

Tahap keempat, menyeleksi alternatif, dilalui kelima partisipan dengan lebih cenderung memilih untuk menjadi misionaris dan masuk sekolah teologia dibandingkan alternatif mereka yang lain. Dalam tahap kelima yakni melakukan evaluasi, membentuk, dan menyusun ulang alternatif dialami partisipan dengan mencari tahu lebih lanjut keuntungan dan kerugian serta tantangan yang harus mereka hadapi jika menjadi seorang misionaris. Partisipan banyak mendapatkan pertimbangan terkait hal ini dari orang-orang terdekat mereka seperti keluarga, teman-teman, dan bahkan pelatih paduan suara. Dari kelima partisipan hanya HM yang tidak melakukan tahap ini sehingga menyebabkan ketika menjalani misi HM pernah berpikir untuk melayani di bidang lain saja seperti mengajar. 
Tahap keenam merupakan tahap membuat keputusan dan melakukan hasil keputusan. Pada tahap ini kelima partisipan mengambil keputusan untuk masuk sekolah teologia dan menjadi misionaris. Tahap ketujuh merupakan tahapan yang terakhir, di tahap ini partisipan melakukan evaluasi atas hasil keputusan mereka dengan mengkaji bagaimana pikiran dan perasaan partisipan setelah menjalani hasil keputusan. Kelima partisipan menyatakan bahwa mereka mengalami kesulitan ketika melakukan peran mereka sebagai misionaris. $\mathrm{R}$ merasa bersyukur, $\mathrm{H}$ memilih untuk 'menangis' dan berdoa kepada Tuhan dalam menghadapi kesulitan, HRS merasa bahwa menjadi misionaris memang merupakan jalan Tuhan, dan D tetap bertahan karena merasa memiliki tanggung jawab atas hasil keputusannya. Sedangkan HM pernah berpikir untuk melayani dalam bidang lain saja seperti mengajar meskipun akhirnya tetap bertahan hingga saat ini. Hal ini dapat terjadi tidak terlepas dari adanya tahapan yang kurang dilakukan HM yakni tahap mengevaluasi alternatif serta melakukan evaluasi, membentuk, dan menyusun ulang alternatif yang mengakibatkan HM hampir tidak memiliki informasi mendalam tentang misionaris dan membuatnya kaget ketika menjalankan misi. Tahapan yang dialami setiap partisipan juga dapat dilihat pada tabel 2 .

Tabel 2. Tahap Pengambilan Keputusan Partisipan

\begin{tabular}{|c|c|c|c|c|c|}
\hline Tahapan & $\mathbf{R}$ & $\mathbf{H}$ & HRS & HM & $\mathbf{D}$ \\
\hline $\mathbf{1}$ & $\begin{array}{l}\text { Membaca Alkitab } \\
\text { Merasa menjadi } \\
\text { pendeta menyenangkan }\end{array}$ & $\begin{array}{l}\text { Aktif melayani } \\
\text { Mengalami konflik }\end{array}$ & $\begin{array}{l}\text { Keluarga } \\
\text { Kristen } \\
\text { Diberitahu oleh } \\
\text { alm. Pendeta K }\end{array}$ & $\begin{array}{l}\text { Ketika SMP melihat } \\
\text { pendeta } \\
\text { Merasa diingatkan } \\
\text { kembali ketika } \\
\text { bekerja }\end{array}$ & $\begin{array}{l}\text { Sejak usia } 15 \\
\text { tahun } \\
\text { Membuat } \\
\text { persekutuan }\end{array}$ \\
\hline 2 & $\begin{array}{l}\text { Merasa malu } \\
\text { Berpikir menjadi } \\
\text { perawat }\end{array}$ & $\begin{array}{l}\text { Karyawan di } \\
\text { perusahaan }\end{array}$ & $\begin{array}{l}\text { Karyawan di } \\
\text { perusahaan } \\
\text { komputer }\end{array}$ & Karyawan pabrik & $\begin{array}{l}\text { Tidak memiliki } \\
\text { alternatif selain } \\
\text { sekolah teologia }\end{array}$ \\
\hline 3 & $\begin{array}{l}\text { Melihat kehidupan } \\
\text { pendeta }\end{array}$ & $\begin{array}{l}\text { Mengikuti sekolah } \\
\text { teologia singkat }\end{array}$ & $\begin{array}{l}\text { Aktif melayani } \\
\text { Bekerja di } \\
\text { yayasan LAI }\end{array}$ & $\begin{array}{l}\text { Kurang memiliki } \\
\text { informasi }\end{array}$ & $\begin{array}{l}\text { Mendapat } \\
\text { informasi dari } \\
\text { teman-teman }\end{array}$ \\
\hline 4 & $\begin{array}{l}\text { Sejak SMA } \\
\text { mendoakan }\end{array}$ & $\begin{array}{l}\text { Mendoakan setelah } \\
\text { mengalami konflik }\end{array}$ & $\begin{array}{l}\text { Mengalami suatu } \\
\text { peristiwa dan } \\
\text { berjanji menjadi } \\
\text { misionaris }\end{array}$ & $\begin{array}{l}\text { Lebih menginginkan } \\
\text { menjadi pendeta }\end{array}$ & $\begin{array}{l}\text { Tidak memiliki } \\
\text { alternatif selain } \\
\text { sekolah teologia }\end{array}$ \\
\hline 5 & $\begin{array}{l}\text { Kakak dan paman } \\
\text { memberi masukan }\end{array}$ & $\begin{array}{l}\text { Diskusi dengan } \\
\text { pelatih paduan } \\
\text { suara }\end{array}$ & $\begin{array}{l}\text { Mendapat } \\
\text { tantangan dari } \\
\text { ayah }\end{array}$ & Tidak mencari tahu & $\begin{array}{l}\text { Tidak memiliki } \\
\text { alternatif selain } \\
\text { sekolah teologia }\end{array}$ \\
\hline 6 & $\begin{array}{l}\text { Masuk sekolah teologia } \\
\text { menjadi misionaris }\end{array}$ & $\begin{array}{l}\text { Masuk sekolah } \\
\text { teologia menjadi } \\
\text { misionaris }\end{array}$ & $\begin{array}{l}\text { Masuk sekolah } \\
\text { teologia menjadi } \\
\text { misionaris }\end{array}$ & Masuk sekolah misi & $\begin{array}{l}\text { Masuk ke sekolah } \\
\text { teologia }\end{array}$ \\
\hline 7 & $\begin{array}{l}\text { Mengalami kesulitan } \\
\text { namun merasa } \\
\text { bersyukur }\end{array}$ & $\begin{array}{l}\text { Mengandalkan } \\
\text { Tuhan ketika } \\
\text { mengalami } \\
\text { kesulitan }\end{array}$ & $\begin{array}{l}\text { Merasa } \\
\text { pelayanannya } \\
\text { sesuai dengan } \\
\text { jalan Tuhan }\end{array}$ & $\begin{array}{l}\text { Pernah berpikir } \\
\text { bahwa melayani } \\
\text { tidak harus sebagai } \\
\text { misionaris }\end{array}$ & $\begin{array}{l}\text { Pernah merasa } \\
\text { kecewa, tetap } \\
\text { bertahan karena } \\
\text { rasa } \\
\text { tanggungjawab }\end{array}$ \\
\hline
\end{tabular}




\section{KESIMPULAN DAN SARAN}

Berdasarkan penelitian yang dilakukan, dapat disimpulkan bahwa setiap partisipan melakukan proses pengambilan keputusan dengan melalui beberapa tahapan yang kurang lebih sama. Secara keseluruhan tahapan tersebut meliputi: (1) mengidentifikasi, mengenal, dan membentuk keputusan; (2) menyusun alternatif; (3) mengevaluasi alternatif; (4) menyeleksi alternatif; (5) melakukan evaluasi, membentuk, dan menyusun ulang alternatif; (6) membuat keputusan dan melakukan hasil keputusan; dan (7) mengevaluasi hasil.

Dalam penelitian ini peneliti banyak membahas mengenai tahapan yang dilalui partisipan selama melakukan proses pengambilan keputusan dan faktor-faktor apa saja yang mempengaruhinya agar mendapatkan gambaran proses pengambilan keputusan seseorang untuk menjadi misionaris.

Dari penelitian ini dapat dilihat bahwa keputusan untuk menjadi seorang misionaris baik di Indonesia maupun di negara lainnya memang bukan hal yang mudah, ada banyak tantangan yang harus dihadapi oleh seorang misionaris Kristen. Melalui hasil penelitian ini juga diketahui bahwa partisipan penelitian paling banyak mendapat informasi akurat terkait misionaris karena aktif dalam melayani di gereja dan mengikuti berbagai kegiatan seperti sekolah teologi singkat, dan lain-lain. Sedangkan, partisipan yang tidak melakukan hal tersebut mengalami kebimbangan ketika menjalankan misi dan bahkan berpikir untuk melayani di bidang lain saja. Oleh karena itu sangat disarankan bagi para calon misionaris untuk aktif dalam kegiatan pelayanan di gereja dan mengikuti kegiatan-kegiatan terkait misi agar mendapat informasi yang akurat dan bisa melakukan tahap evaluasi alternatif dengan baik.

Saran bagi setiap pembaca yang ingin melakukan pengambilan keputusan dalam kehidupannya, terutama keputusan-keputusan yang penting, adalah agar dapat mengikuti tahap- tahap pengambilan keputusan secara lengkap. Saran ini dimaksudkan agar pembaca mendapatkan informasi secara menyeluruh dan detail sehingga proses pengambilan keputusan bisa dilakukan dengan baik serta meningkatkan peluang untuk mendapatkan hasil akhir yang memang diinginkan.

\section{Ucapan Terima Kasih (Acknowledgement)}

Puji Tuhan kepada Tuhan karena atas anugerah-Nya penelitian ini dapat tersusun hingga selesai. Dalam kesempatan ini peneliti ingin berterima kasih kepada semua pihak yang telah membantu dan mendukung penulisan skripsi ini baik secara langsung maupun tidak langsung. Terima kasih kepada Dr. Raja Oloan Tumanggor selaku dosen pembimbing yang telah meluangkan waktu untuk membimbing penulisan penelitian. Terima kasih kepada keluarga yang memberikan dukungan kepada peneliti. Terima kasih juga kepada teman peneliti yang senantiasa memberikan dukungan moral dan terus mendorong peneliti sehingga dapat menyelesaikan penulisan skripsi ini. Pada akhirnya peneliti berharap agar penelitian ini dapat memberikan tambahan informasi yang berarti bagi bidang ilmu psikologi, terutama psikologi agama serta bermanfaat bagi seluruh pembaca.

\section{REFERENSI}

Bosch, B. (2014). Outcomes and conclusions of the survey for missionaries. Diunduh dari http://thrivingmember.com

DuBrin, A. J. (1978). Fundamentals of organizational behavior: An applied perspective. NY: Pergamon Press Inc.

DuBrin, A. J. (2012). Essentials of management. Cincinnati (12 ${ }^{\text {th }}$ ed.). OH: South-Western Pub. Co.

Halpern, D. F. (2014). Thought and knowledge: an introduction to critical thinking. $5^{\text {th }}$ ed. New York, NY: Psychology Press. 
Hibbert, R., Hibbert, E., \& Silberman, T. (2015). The journey towards long-term missionary service: How Australian missionaries are being called and choose mission agencies. Missiology, 43(4), 469-482. https://doi.org/10.1177\%2F0091829615584189

Hoon, C. Y. (2013). Between evangelism and multiculturalism: The dynamics of Protestant Christianity in Indonesia. Social Compass, 60(4), 457-470. https://doi.org/10.1177\%2F0037768613502758

Siebert, J. U., \& Kunz, R. E., \& Rolf, P. (2019). Effects of proactive decision making on life satisfaction. European Journal of Operational Research, 280(3), 1171-1187. https://doi.org/10.1016/j.ejor.2019.08.011

Tumanggor, R. O. (2014). Misi dalam masyarakat majemuk. Genta Pustaka Lestari. 